\title{
Interaction of Chloride and Bicarbonate Transport across the Basolateral Membrane of Rabbit Proximal Straight Tubule

\author{
Evidence for Sodium Coupled Chloride/Bicarbonate Exchange
}

Sei Sasaki and Naoki Yoshiyama

Department of Internal Medicine, Tokyo Medical and Dental University, Tokyo 113, Japan

\begin{abstract}
The existence of chloride/bicarbonate exchange across the basolateral membrane and its physiologic significance were examined in rabbit proximal tubules. $S_{2}$ segments of the proximal straight tubule were perfused in vitro and changes in intracellular pH (pHi) and chloride activity $\left(\mathrm{a}_{\mathrm{c}}{ }^{\mathbf{j}}\right)$ were monitored by double-barreled microelectrodes. Total peritubular chloride replacement with gluconate increased $\mathrm{pHi}$ by 0.8 , and this change was inhibited by a pretreatment with an anion transport inhibitor, SITS. Peritubular bicarbonate reduction increased $\mathbf{a}_{\mathbf{c}} \mathbf{i}$, and most of this increase was lost when ambient sodium was totally removed. The reduction rates of $\mathrm{pHi}$ induced by a peritubular bicarbonate reduction or sodium removal were attenuated by $20 \%$ by withdrawal of ambient chloride. SITS application to the bath in the control condition quickly increased pHi, but did not change $a_{c i}^{i}$. However, the $a_{c i}^{i}$ slightly decreased in response to SITS when the basolateral bicarbonate efflux was increased by reducing peritubular bicarbonate concentration. It is concluded that sodium coupled chloride/bicarbonate exchange is present in parallel with sodium-bicarbonate cotransport in the basolateral membrane of the rabbit proximal tubule, and it contributes to the basolateral bicarbonate and chloride transport.
\end{abstract}

\section{Introduction}

There is growing evidence that most of bicarbonate transport across the basolateral membrane (BLM) ${ }^{1}$ of the renal proximal tubule cells is mediated by rheogenic $\mathrm{Na}-\mathrm{HCO}_{3}$ cotransport (1-8). However, it has not been well examined whether there is a chloride dependent bicarbonate flux across BLM of the proximal tubule. It is interesting that a chloride coupled $\mathrm{Na}$ $\mathrm{HCO}_{3}$ cotransport mechanism $\left(\mathrm{Na}-\mathrm{HCO}_{3} / \mathrm{Cl}\right.$ exchange) has been identified in the snail neuron (9), squid axon (10), barnacle muscle fiber (11), and cultured fibroblast (12). Guggino et

Address reprint requests to Dr. Sasaki, Second Department of Internal Medicine, Tokyo Medical and Dental University, Bunkyo-Ku, Yushima, Tokyo 113, Japan.

Received for publication 1 September 1987 and in revised form 23 November 1987.

1. Abbreviations used in this paper: $\mathrm{a}_{\mathrm{C}}^{\mathrm{i}}$, intracellular chloride activity; BLM, basolateral membrane; pHi, intracellular pH; PST, proximal straight tubules; RpHi, pHi reduction rates; SITS, 4-acetamido-4'isothiocyanostilbene-2,2'-disulfonic acid; $\mathrm{Vbl}$, basolateral membrane potential.

\section{J. Clin. Invest.}

(c) The American Society for Clinical Investigation, Inc.

0021-9738/88/04/1004/08 \$2.00

Volume 81, April 1988, 1004-1011 al. demonstrated the existence of an $\mathrm{Na}-\mathrm{HCO}_{3} / \mathrm{Cl}$ exchange mechanism in BLM of Necturus proximal tubules, and he concluded that most of the basolateral chloride transport is mediated by this mechanism (13). In the previous study (8), we observed that the intracellular $\mathrm{pH}(\mathrm{pHi})$ of rabbit proximal straight tubules (PST) increased when chloride of the basolateral fluid was totally removed. This observation was consistent with a chloride/bicarbonate exchange mechanism. If this kind of exchange exists, it is conceivable that the exchange plays some role in both bicarbonate and chloride transport across BLM of the proximal tubule.

The aim of this study was to define whether chloride coupled bicarbonate transport exists in BLM of $S_{2}$ segment of rabbit PST. We monitored pHi and intracellular chloride activity $\left(a_{C l}{ }^{i}\right)$ of PST cells when compositions of ambient fluid were rapidly changed. Our data demonstrated the existence of a sodium coupled chloride/bicarbonate exchange mechanism ( $\mathrm{Na}-\mathrm{HCO}_{3} / \mathrm{Cl}$ exchange) across BLM.

\section{Methods}

Isolated segments of rabbit PST were dissected and perfused as previously described $(7,8,14)$. Briefly, the proximal portions of PST $\left(\mathrm{S}_{2}\right.$ segment) were dissected in cooled $\left(4^{\circ} \mathrm{C}\right)$ A solution (Table I) and were then transferred to the bath. To achieve a rapid bath fluid exchange, bath volume was reduced to $0.1 \mathrm{ml}$, and bath fluid was continuously changed at $5-10 \mathrm{ml} / \mathrm{min}$. This resulted in a complete bath exchange within $5 \mathrm{~s}$. The bath fluid was preheated to $38^{\circ} \mathrm{C}$. The composition of artificial solutions used in this study is shown in Table I. These solutions were bubbled with $5 \% \mathrm{CO}_{2} / 95 \% \mathrm{O}_{2}$ gas, and their osmolarities were adjusted to $290 \mathrm{mosmol} / \mathrm{kg} \mathrm{H}_{2} \mathrm{O}$ by adding principal salts or water.

Basolateral membrane potential $(\mathrm{bl}), \mathrm{pHi}$, and $\mathrm{a}_{\mathrm{c}}^{\mathrm{i}}$ were measured by double-barreled micro $\mathrm{pH}$ and $\mathrm{Cl}^{-}$electrodes. The method of making double-barreled ion-selective microelectrodes was described elsewhere $(7,8)$. Double-barreled borosilicate glass tubing of unequal diameter (fiber-containing; Hilgenberg, FRG) was pulled on a horizontal microelectrode puller. The larger barrel (1.5 mm OD, $0.87 \mathrm{~mm} \mathrm{ID)}$ was used for the ion-selective electrode, and the smaller barrel $(0.75$ $\mathrm{mm}$ OD, $0.35 \mathrm{~mm}$ ID) was used for the reference electrode. The inside of the large barrel was made hydrophobic by silane vapor, and the tip portion was backfilled with either $\mathrm{H}^{+}$ligand (15), or $\mathrm{Cl}^{-}$ligand (Corning 477913; Corning Glass Works, Corning, NY). The reference barrel of the pH electrode was filled with $0.5 \mathrm{M} \mathrm{KCl}$ and that of the $\mathrm{Cl}^{-}$ electrode with $0.5 \mathrm{M} \mathrm{K}_{2} \mathrm{SO}_{4}+10 \mathrm{mM} \mathrm{KCl}$ solution. $\mathrm{Ag}-\mathrm{AgCl}$ wires were inserted into the barrels and the electrode was mounted on a micromanipulator (Leitz, FRG).

The calibration method and general characteristics of $\mathrm{pH}$ electrodes used in this study were the same as those reported previously (7). General characteristics of the $\mathrm{Cl}^{-}$electrode were recently reported from this laboratory (16). The electrical resistance of the $\mathrm{Cl}^{-}$-selective barrel ranged from 2 to $5 \times 10^{10} \mathrm{ohm}$, and the response time $(95 \%$ voltage change) was within $2 \mathrm{~s}$. The slope of the response was 55-60 $\mathrm{mV} / 10$-fold change in $\mathrm{Cl}^{-}$activity. The selectivity coefficients for other anions $\left(\mathrm{K}_{\mathrm{Cl}, \text { anion }}\right)$ that were determined in the previous study (16) were, 
Table I. Composition of Artificial Solutions (mM)

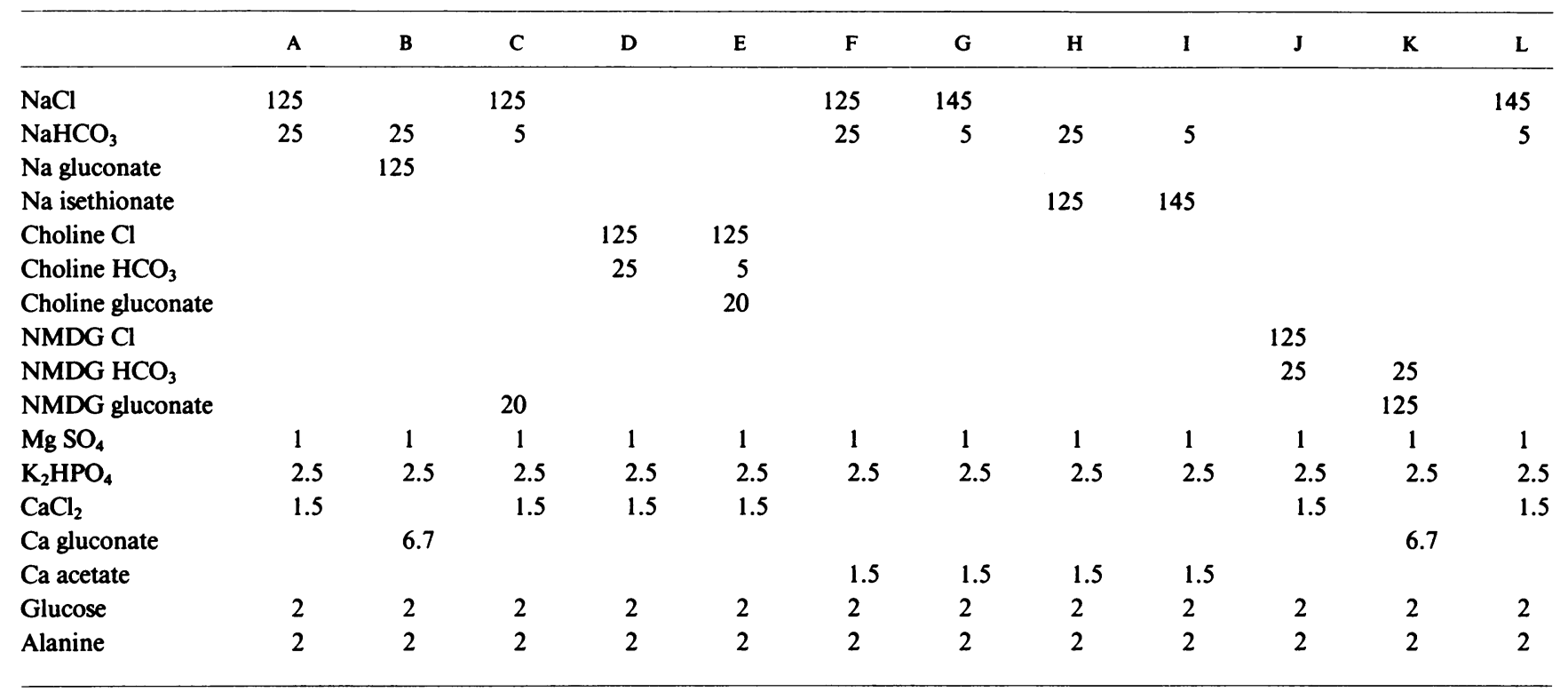

All solutions were bubbled with $5 \% \mathrm{CO}_{2} / 95 \% \mathrm{O}_{2}$ gas. NMDG, $N$-methyl-D-glucammonium.

$\mathrm{K}_{\mathrm{Cl}_{1} \mathrm{HCO}_{3}}: 0.11, \mathrm{~K}_{\mathrm{Cl}_{1, g l u c o n a t e}}: 0.03, \mathrm{~K}_{\mathrm{Cl}, \text { isethionate: }}: 0.14$. The $\mathrm{a}_{\mathrm{Cl}}{ }^{i}$ was calculated as

$\mathrm{a}_{\mathrm{C}}{ }^{\mathrm{i}}=\left(\mathrm{Clb}+\mathrm{K}_{\mathrm{Cl}, \mathrm{HCO}} \times \mathrm{HCO}_{3} \mathrm{~b}\right) \times 10^{h \mathrm{Cl} / \mathrm{s}}$

where $\mathrm{Clb}$ and $\mathrm{HCO}_{3} \mathrm{~b}$ are $\mathrm{Cl}^{-}$and $\mathrm{HCO}_{3}^{-}$activities of the bath fluid, respectively. $\mathrm{VCl}$ is the differential output between the voltages recorded by the $\mathrm{Cl}^{-}$selective and reference barrels and $S$ is the slope of the voltage response of $\mathrm{Cl}^{-}$electrode. It is possible that unmeasurable intracellular anions interact with the $\mathrm{Cl}^{-}$electrode resulting in an overestimation of $a_{c}{ }^{i}$ values. In our previous study (16), we measured $a_{C}{ }^{i}$ of PST in the total absence of ambient $\mathrm{Cl}^{-}$(gluconate replacement), and found $4.2 \mathrm{mM}$ of unmeasurable anions. We did not substract this value from the measured $a_{c}{ }^{i}$ values in this study. Thus, all $a_{c}{ }^{i}$ values reported in this paper are not the corrected values. The electrical potentials (reference and ion-selective electrodes) were measured with an electrometer (FD223; W-P Instruments, New Haven, CT) and recorded simultaneously on a two-pen chart recorder (R-20, Rika Denki, Tokyo, Japan). A common bath reference electrode was a $3-\mathrm{M} \mathrm{KCl}$ flowing electrode in a direct contact with the exit of bath solution to make a liquid junction potential negligibly small.

The data are expressed as means $\pm S E$. For intracellular measurements, $n$ equals the number of cells. Only one intracellular measurement was performed in each tubule. Student's $t$ test was used to determine statistical significance.

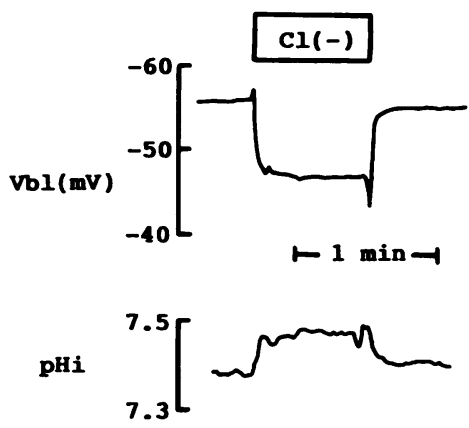

Figure 1. Effect of total bath chloride replacement with gluconate on $V \mathrm{bl}$ and pHi. A chloride free period is denoted by $\mathrm{Cl}(-)$.

\section{Results}

Effect of bath $\mathrm{Cl}^{-}$elimination on $\mathrm{pHi}$. We have previously reported that total bath $\mathrm{Cl}^{-}$replacement with isethionate depolarized $V \mathrm{bl}$ by $4.5 \mathrm{mV}$ and alkalinized pHi by $0.06(8)$. It is possible that this effect is not due to $\mathrm{Cl}^{-}$removal, but due to the isethionate addition. To deny this possibility, we performed studies in which bath $\mathrm{Cl}^{-}$was replaced with another anion, gluconate. In the experiment shown in Fig. 1, total bath $\mathrm{Cl}^{-}$replacement with gluconate (solutions A and B) depolarized $V \mathrm{bl}$ by $9.0 \mathrm{mV}$ and alkalinized pHi by 1.0 . A summary of eight such studies is given in Table II. These results are essentially the same as those in the previously reported isethionate study, indicating that the effect of bath $\mathrm{Cl}^{-}$removal is due to the $\mathrm{Cl}^{-}$elimination rather than to the addition of substituting anions.

Then, we examined whether this bath $\mathrm{Cl}^{-}$removal related cell alkalinization is inhibitable with the anion transport inhibitor, 4-acetamido-4'-isothiocyanostilbene-2,2'-disulfonic acid (SITS). Fig. 2 shows one such experiment. SITS $(0.5 \mathrm{mM})$ was added to the bath before $\mathrm{a} \mathrm{Cl}^{-}$removal study, and $>4 \mathrm{~min}$ was

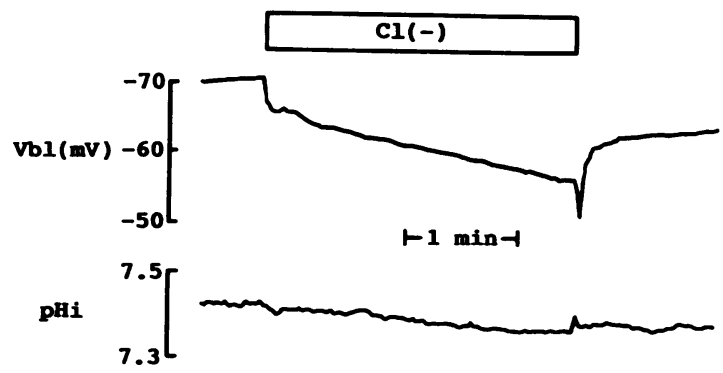

Figure 2. Effect of total bath chloride removal in the presence of SITS. SITS $(0.5 \mathrm{mM})$ was added to the bath prior to the bath chloride removal, and it was present through the study. 
allowed as an equilibration period. The addition of SITS to the bath caused a hyperpolarization of $\mathrm{Vbl}$ as previously reported by Biagi (2) and an alkalinization of $\mathrm{pHi}$. The bath $\mathrm{Cl}^{-}$removal performed in this condition caused an initial rapid depolarization of $\mathrm{Vbl}$ by $4 \mathrm{mV}$, which was followed by a gradual depolarization. The initial $V \mathrm{bl}$ depolarization may be due to a circular current flow generated by a diffusion potential at the tight junction as considered in our previous study (8). The mechanism of the later depolarization is not clear at present. Bath $\mathrm{Cl}^{-}$removal did not cause any change in $\mathrm{pHi}$, demonstrating that the cell alkalinization induced by bath $\mathrm{Cl}^{-}$removal was prevented with SITS pretreatment. A summary of five studies is also given in Table II. The initial $V$ bl depolarization was smaller in SITS-treated group than in normal group (1.6 vs. $8.1 \mathrm{mV}$; Table II). The reason for this difference is not clear, but it may be due to alterations of membrane resistance of the luminal and basolateral membranes, and the shunt pathway, or both.

Effect of reducing bath $\mathrm{HCO}_{3}^{-}$on $a_{C l}{ }^{i}$. The results described above indicate the existence of an exchange mechanism of $\mathrm{Cl}^{-}$ and $\mathrm{HCO}_{3}^{-}$(or related base) at BLM of $\mathrm{S}_{2}$ cells. If this exchanger exists, it is anticipated that an alteration of bath $\mathrm{HCO}_{3}^{-}$ should change $a_{c l}{ }^{i}$. To examine this prediction, $a_{c l}{ }^{i}$ was monitored and bath $\mathrm{HCO}_{3}^{-}$was reduced from 25 to $5 \mathrm{mM}$ (solutions $\mathrm{A}$ and $\mathrm{C}$ ). Bath $\mathrm{HCO}_{3}^{-}$was replaced by gluconate to maintain bath $\mathrm{Cl}^{-}$concentration constant. As shown in Fig. 3, bath $\mathrm{HCO}_{3}^{-}$reduction caused a large and sharp depolarization of $\mathrm{Vbl}$ and an increase in $\mathrm{a}_{\mathrm{Cl}} \mathrm{i}$. This $\mathrm{Vbl}$ depolarization could be due to the rheogenic $\mathrm{Na}-\mathrm{HCO}_{3}$ cotransport. As summarized in Table III, the results of eight studies showed that $V \mathrm{bl}$ instantaneously depolarized by $34 \mathrm{mV}$ and that $\mathrm{a}_{\mathrm{Cl}}{ }^{\mathrm{i}}$ increased from 25.5 to $47.6 \mathrm{mM}$ (the maximum peak value). These changes were all significant. This increase in $a_{C l}{ }^{i}$ is consistent with the presence of $\mathrm{Cl} / \mathrm{HCO}_{3}$ exchange.

We next examined whether this $a_{c}{ }^{i}$ increase in response to bath $\mathrm{HCO}_{3}^{-}$reduction can be observed in the nominal absence of ambient $\mathrm{Na}^{+}$(solutions $\mathrm{D}$ and $\mathrm{E}$ ). $\mathrm{Na}^{+}$of luminal and bath fluids was substituted with choline. In a low $\mathrm{HCO}_{3}^{-}$solution, $20 \mathrm{mM}$ of $\mathrm{HCO}_{3}^{-}$was replaced with gluconate to keep $\mathrm{Cl}^{-}$ constant. A representative experiment is shown in Fig. 4. In the absence of $\mathrm{Na}^{+}$, bath $\mathrm{HCO}_{3}^{-}$reduction from 25 to $5 \mathrm{mM}$ caused a small depolarization of $\mathrm{Vbl}$ and a gradual but small increase in $a_{c 1}$. A summary of five studies (Table III) was that $a_{\mathrm{Cl}^{i}}$ increased from 30.5 to $34.2 \mathrm{mM}$ (peak values, $P<0.02$ ).

Table II. Effect of Bath Chloride Removal

\begin{tabular}{lcl}
\hline & \multicolumn{1}{c}{$\mathrm{Vbl}$} & $\mathrm{pHi}$ \\
\hline & $m V$ & \\
Control $(n=8)$ & $-46.6 \pm 2.4$ & $7.36 \pm 0.01$ \\
$\mathrm{Cl}(-)$ & $-38.5 \pm 3.1^{*}$ & $7.44 \pm 0.02^{*}$ \\
$\operatorname{SITS}(n=5)$ & $-72.6 \pm 0.9$ & $7.45 \pm 0.04$ \\
$\mathrm{Cl}(-)$ & $-71.0 \pm 1.4$ & $7.45 \pm 0.04$
\end{tabular}

$* P<0.05$.

$\mathrm{Cl}(-)$ denotes the studies where total bath $\mathrm{Cl}^{-}$was replaced with gluconate.

$\mathrm{Wb}$ and $\mathrm{pHi}$ values of $\mathrm{Cl}(-)$ are the values when $\mathrm{Vbl}$ initially depolarized, and pHi reached the maximum after bath $\mathrm{Cl}^{-}$removal, respectively.

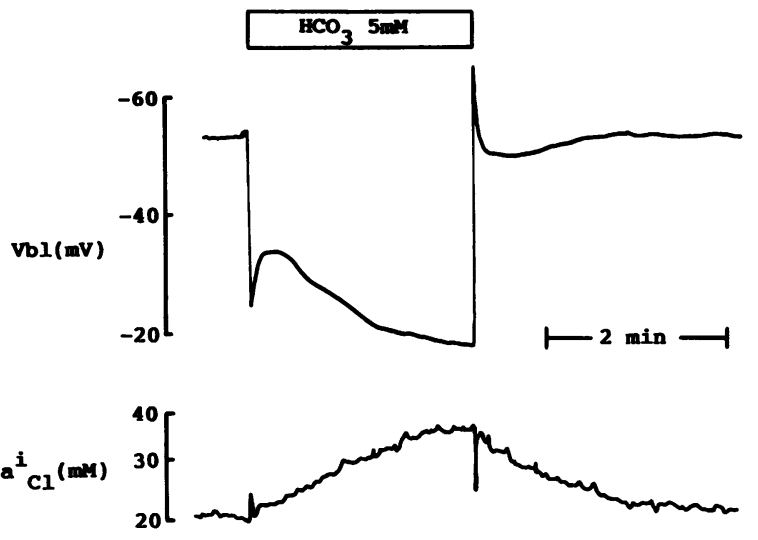

Figure 3. Effect of bath bicarbonate reduction from 25 to $5 \mathrm{mM}$ on $\mathrm{Vbl}$ and $\mathrm{a}_{\mathrm{c}} \mathrm{i}$. Bath bicarbonate was substituted with gluconate to keep chloride constant.

This $a_{c 1}{ }^{i}$ increase was clearly smaller than that observed in the presence of $\mathrm{Na}^{+}$(Table III, and compare Figs. 3 and 4).

Reduction rates of $p \mathrm{Hi}$ in the presence and absence of $\mathrm{Cl}^{2}$. To confirm that $\mathrm{Cl}^{-}$interacts with basolateral $\mathrm{HCO}_{3}^{-}$transport, the reduction of $\mathrm{pHi}$ induced by either bath $\mathrm{HCO}_{3}^{-}$reduction or bath $\mathrm{Na}^{+}$removal were compared in the presence and absence of ambient $\mathrm{Cl}^{-}$. As shown in Fig. 5, bath $\mathrm{HCO}_{3}^{-}$ reduction from 25 to $5 \mathrm{mM}$ (at constant $\mathrm{pCO}_{2}$ ) was repeated twice; first, in the presence of $\mathrm{Cl}^{-}$and second, in the total absence of $\mathrm{Cl}^{-}$(solutions $\mathrm{F}-\mathrm{H}$, and I). Bath $\mathrm{HCO}_{3}^{-}$reduction caused both a large and sharp depolarization of $\mathrm{Vbl}$ and a reduction in pHi in the presence and absence of ambient $\mathrm{Cl}^{-}$. However, an inspection of Fig. 5 shows that pHi reduction induced by lowering bath $\mathrm{HCO}_{3}^{-}$was slightly smaller in the absence of $\mathrm{Cl}^{-}$than in the presence of $\mathrm{Cl}^{-}$. To quantify this effect, the initial $\mathrm{pHi}$ reduction rate $(\mathrm{RpHi} ; \mathrm{pH} / \mathrm{min})$ was measured. $\mathrm{RpHi}$ was measured as $\left(\mathrm{pHi}^{0}-\mathrm{pHi}^{10}\right) \times(1 / 6 \mathrm{~min})^{-1}$, where $\mathrm{pHi}^{0}$ and $\mathrm{pHi}^{10}$ were the $\mathrm{pHi}$ values at the start and $10 \mathrm{~s}$ after the bath $\mathrm{HCO}_{3}^{-}$reduction, respectively. Because our $\mathrm{pH}$ electrodes possessed some time delay in response, $\mathrm{RpHi}$ would be slightly underestimated. This underestimation did not affect our interpretation of the data because the study was a paired study, and the same electrode was used through each pair. The data are summarized in Fig. 6. Removal of ambient $\mathrm{Cl}^{-}$slowed $\mathrm{RpHi}$ by $26 \%$ from $1.80 \pm 0.13$ to $1.33 \pm 0.06 \mathrm{pH} /$

Table III. Effect of Bath Bicarbonate Reduction on $a_{C l}{ }^{i}$

\begin{tabular}{lcc}
$\longrightarrow$ & $\mathrm{Vbl}$ & \multicolumn{1}{c}{$\mathrm{ac}^{\mathrm{i}}$} \\
\hline & $m V$ & $m M$ \\
Control $(n=8)$ & $-46.5 \pm 2.6$ & $25.5 \pm 2.3$ \\
$\mathrm{HCO}_{3}^{-} 5 \mathrm{mM}$ & $-12.6 \pm 4.8^{*}$ & $47.6 \pm 4.1^{*}$ \\
$\mathrm{Na}+$ free $(n=5)$ & $-36.8 \pm 3.4$ & $30.5 \pm 3.9$ \\
$\mathrm{HCO}_{3}^{-} 5 \mathrm{mM}$ & $-34.8 \pm 3.4$ & $34.2 \pm 4.0^{*}$
\end{tabular}

$* P<0.05$.

$\mathrm{HCO}_{3}^{-} 5 \mathrm{mM}$ : bath $\mathrm{HCO}_{3}^{-}$was reduced to $5 \mathrm{mM}$ by replacing with $20 \mathrm{mM}$ gluconate to keep bath $\mathrm{Cl}^{-}$constant.

$V \mathrm{bl}$ and $\mathrm{a}_{\mathrm{c}}{ }^{\mathrm{i}}$ values are the values when $\mathrm{Vb}$ initially depolarized, and $\mathrm{a}_{\mathrm{C}}{ }^{\mathrm{i}}$ reached the maximum after bath $\mathrm{HCO}_{3}^{-}$reduction, respectively. 

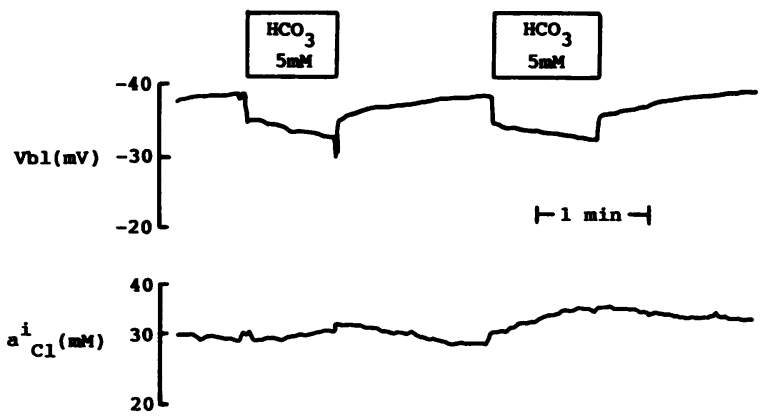

Figure 4. Effect of bath bicarbonate reduction in the absence of sodium. Experiment was performed in the total absence of ambient sodium (choline substitution), and bicarbonate was substituted with gluconate to keep chloride constant.

$\min (n=6, P<0.01)$. These experiments were performed in the order where the control period always preceded the $\mathrm{Cl}^{-}$free period. It was possible that the attenuation of the $\mathrm{RpHi}$ would be due to a time-dependent process rather than to a specific $\mathrm{Cl}^{-}$effect. To deny this possibility, we performed the time control study where bath $\mathrm{HCO}_{3}^{-}$reduction was performed twice in the presence of ambient $\mathrm{Cl}^{-}$. Five such studies showed that RpHi did not change in the first and second trials $(1.97 \pm 0.30$ vs. $1.96 \pm 0.27 \mathrm{pH} / \mathrm{min})$.

The above result indicated that $\mathrm{Cl}^{-}$removal affects the $\mathrm{HCO}_{3}^{-}$flux, which is induced by bath $\mathrm{HCO}_{3}^{-}$reduction. To determine whether this $\mathrm{Cl}^{-}$-sensitive $\mathrm{HCO}_{3}^{-}$flux is mediated by a $\mathrm{Na}^{+}$-dependent process, the $\mathrm{RpHi}$ induced by bath $\mathrm{Na}^{+}$ removal was also compared in the presence and absence of ambient $\mathrm{Cl}^{-}$(solutions A, B, J, and $\mathrm{K}$ ). A representative experiment is shown in Fig. 7. The result was almost identical to that observed when bath $\mathrm{HCO}_{3}^{-}$was reduced (Fig. 5). The removal of ambient $\mathrm{Cl}^{-}$slowed $\mathrm{RpHi}$ by $19 \%$ from $1.78 \pm 0.30$ to $1.44 \pm 0.20 \mathrm{pH} / \mathrm{min}(P<0.05, n=6)$. A summary of the data (Fig. 6) demonstrates that ambient $\mathrm{Cl}^{-}$removal slowed $\mathrm{RpHi}$ to a comparable degree when either bath $\mathrm{HCO}_{3}^{-}$was reduced or $\mathrm{Na}^{+}$was removed indicating that $\mathrm{Cl}^{-}$sensitive $\mathrm{HCO}_{3}^{-}$flux is probably coupled to a $\mathrm{Na}-\mathrm{HCO}_{3}$ cotransport (Na- $\mathrm{HCO}_{3} / \mathrm{Cl}$ exchange). ${ }^{2}$

Effect of SITS application to the bath on pHi and $a_{C l}{ }^{i}$. The results thus far indicate the existence of $\mathrm{Na}-\mathrm{HCO}_{3} / \mathrm{Cl}$ exchange in BLM (see Discussion). In order to determine the roles of this exchanger, SITS was rapidly applied to the bath. SITS has been shown to inhibit both the $\mathrm{Na}-\mathrm{HCO}_{3}$ cotransport and $\mathrm{Na}-$ $\mathrm{HCO}_{3} / \mathrm{Cl}$ exchange in BLM of renal proximal tubules (1-13, 17). Our prediction was that if $\mathrm{Na}-\mathrm{HCO}_{3} / \mathrm{Cl}$ exchange contributes to the basolateral $\mathrm{HCO}_{3}^{-}$and $\mathrm{Cl}^{-}$fluxes in the steady-state condition, a sudden stop of the exchange will alter $\mathrm{pHi}$ and $\mathrm{acc}_{\mathrm{c}} \mathrm{i}$.

Fig. $8 \mathrm{~A}$ shows an experiment where the effect on pHi of 0.5 $\mathrm{mM}$ SITS applied to the bath was examined. SITS application induced an abrupt increase in $\mathrm{Vbl}$ by $3 \mathrm{mV}$, which was fol-

2. We interpreted the effect of $\mathrm{Cl}^{-}$removal on $\mathrm{RpHi}$ as indicating evidence for direct coupling of $\mathrm{Cl}^{-}$and Na- $\mathrm{HCO}_{3}$ cotransport. However, we have to note that other secondary effects of $\mathrm{Cl}^{-}$removal such as alterations in cell functions and luminal $\mathrm{H}^{+}$secretion rates might induce the same result. For example, if $\mathrm{Cl}^{-}$removal reduces metabolic acid production (by inhibiting $\mathrm{Na}^{+}$transport), then $\mathrm{RpHi}$ induced by $\mathrm{HCO}_{3}^{-}$or $\mathrm{Na}^{+}$removal may be small in $\mathrm{Cl}^{-}$free condition because cell acid load is less. At present we cannot neglect these possibilities.
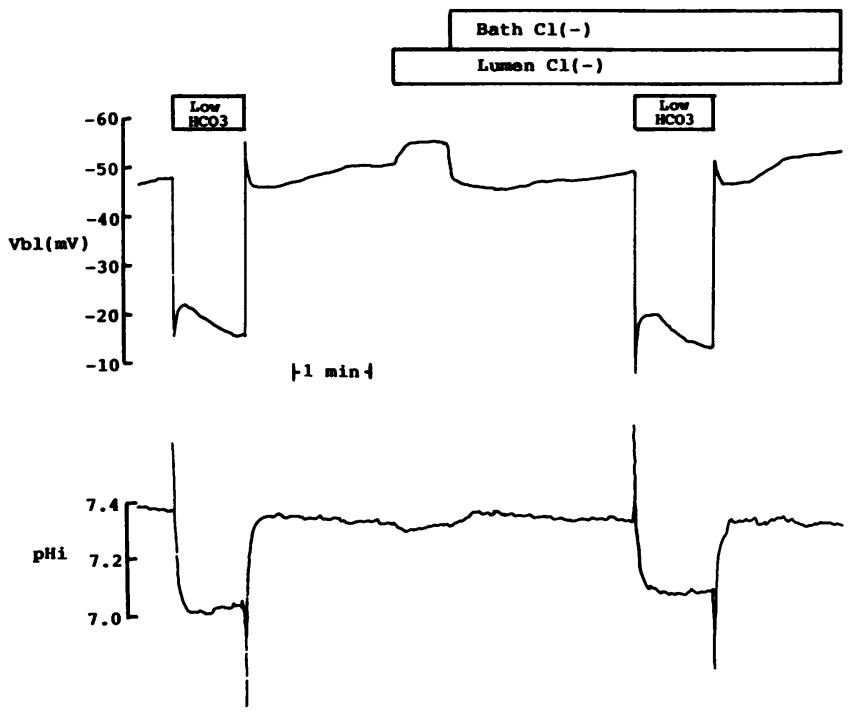

Figure 5. Effect of lowering bath bicarbonate from 25 to $5 \mathrm{mM}$ in the presence and absence of ambient chloride. Bath bicarbonate reduction was performed twice. After the first bicarbonate reduction, both luminal and bath fluids were changed to chloride-free solution, and the second bicarbonate reduction was repeated.

lowed by a gradual hyperpolarization. pHi also quickly increased by 0.9 in response to SITS application, and it further increased gradually in the late phase. A summary of seven such experiments is given in Table IV. The above results indicate that $S_{2}$ cells in the control condition continuously transport $\mathrm{HCO}_{3}^{-}$across BLM from the cell to the peritubular fluid via SITS inhibitable transport mechanisms, presumably the Na$\mathrm{HCO}_{3}$ cotransport. The abrupt $\mathrm{Vbl}$ hyperpolarization is also consistent with the $\mathrm{Na}-\mathrm{HCO}_{3}$ cotransport mechanism because this transporter has been shown to be rheogenic (1-8).

Fig. $8 B$ is an example of the study where the effect of SITS on $a_{C}{ }^{i}$ was examined. As clearly shown in the figure, SITS application induced a quick hyperpolarization of $\mathrm{Vbl}$ (same as in Fig. $8 A$ ), but did not change $a_{C}{ }^{i}$ appreciably. A summary of this protocol is shown in Table IV. This result may indicate that basolateral $\mathrm{Cl}^{-}$flux mediated by the $\mathrm{Na}-\mathrm{HCO}_{3} / \mathrm{Cl}$ exchange is not significant (see Discussion).

We further examined the possible contribution of a basolateral $\mathrm{Na}-\mathrm{HCO}_{3} / \mathrm{Cl}$ exchange in the condition where transcel-

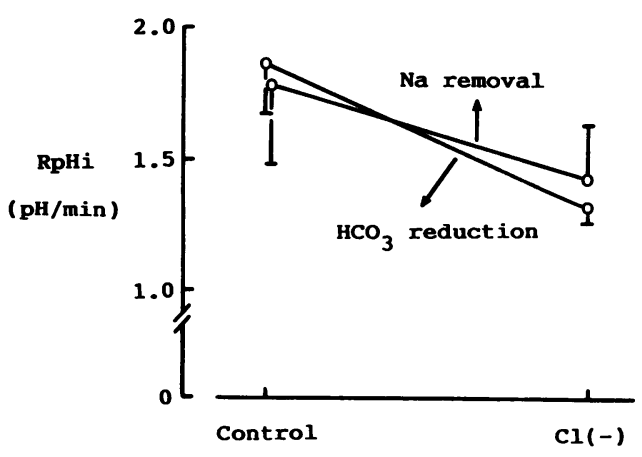

Figure 6. A summary of pHi reduction rates $(\mathrm{RpHi})$ induced by bath bicarbonate reduction ( 25 to $5 \mathrm{mM}$ ) or bath sodium removal in the presence and absence of chloride. 


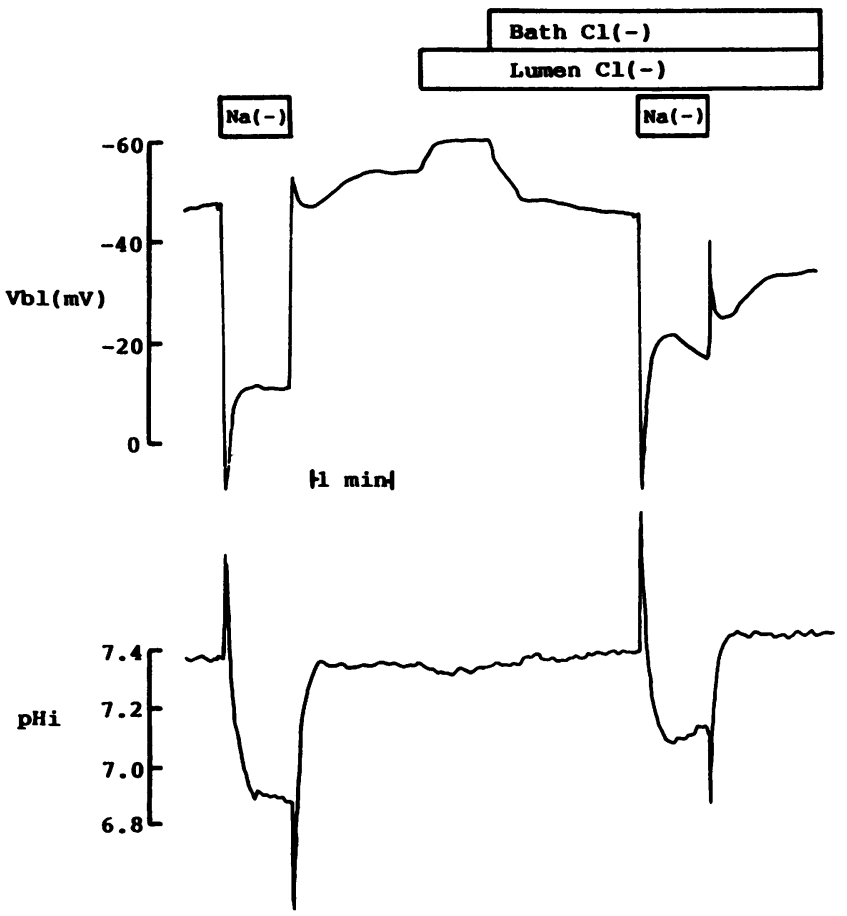

Figure 7. Effect of the total removal of bath sodium in the presence and absence of ambient chloride. Bath sodium removal was performed twice; first, in the presence of chloride, and second, in the total absence of chloride (lumen and bath).

lular $\mathrm{Cl}^{-}$transport is stimulated. For this purpose, a high $\mathrm{Cl}^{-}$, low $\mathrm{HCO}_{3}^{-}$, and formate containing solution (solution $\mathrm{L}$ + formate $1 \mathrm{mM}$ ) was used as a luminal perfusate. Recently Schild et al. (18) clearly demonstrated that the addition of formate to a high $\mathrm{Cl}^{-}$, low $\mathrm{HCO}_{3}^{-}$luminal fluid increased transcellular $\mathrm{Cl}^{-}$transport in the rabbit $\mathrm{S}_{2}$ segment. As summarized in Table IV, SITS application to the tubule that was perfused with the formate containing luminal perfusate did not change $\mathrm{a}_{\mathrm{C}} \mathrm{i}$ as well.

Finally, we examined the possibility that the $\mathrm{Na}-\mathrm{HCO}_{3} / \mathrm{Cl}$ exchange contributes as a $\mathrm{HCO}_{3}^{-}$exit mechanism when basolateral $\mathrm{HCO}_{3}^{-}$transport is stimulated. To stimulate basolateral $\mathrm{HCO}_{3}^{-}$transport, low $\mathrm{HCO}_{3}^{-}$solution (solution $\mathrm{L}$ ) was used as a bath fluid. As shown in Fig. 9, an application of SITS in this condition caused a sharp and large hyperpolarization of $\mathrm{Vbl}$ and decreased $\mathrm{ac}_{\mathrm{c}}{ }^{\mathrm{a}}$ slightly. A summary of the data (Table IV) shows that $a_{c}{ }^{i}$ decreased significantly by $3 \mathrm{mM}$ in response to SITS application. $V$ bl hyperpolarization induced by SITS addition was large in this protocol compared with that observed when the bath fluid was the control solution (15.2 vs. $3.3 \mathrm{mV}$, Table IV). The difference is in accord with our view that this $\mathrm{Vbl}$ hyperpolarization is due to the rheogenic $\mathrm{Na}-\mathrm{HCO}_{3}$ cotransport. Interestingly, effects of SITS on $\mathrm{Vbl}$ and $\mathrm{a}_{\mathrm{cl}}{ }^{\mathrm{i}}$ were reversible, indicating that SITS effects may not be due to a covalent binding of SITS to the transporter. The observed reduction in $\mathrm{ac}^{\mathrm{i}}$ in response to SITS addition indicates that the $\mathrm{Na}-\mathrm{HCO}_{3} / \mathrm{Cl}$ exchanger works as a $\mathrm{HCO}_{3}^{-}$exit mechanism when basolateral $\mathrm{HCO}_{3}^{-}$efflux is stimulated.

\section{Discussion}

Mechanisms of the interaction of $\mathrm{Cl}^{-}$and $\mathrm{HCO}_{3}^{-}$transport. Recently, $\mathrm{HCO}_{3}^{-}$transport across BLM in renal proximal tubule cells has been shown to be mediated by a $\mathrm{Na}-\mathrm{HCO}_{3}$ cotransport in amphibian (1) and mammals $(2-8,19)$. This transport is known to be rheogenic due to a stoichiometry of $\mathrm{HCO}_{3} / \mathrm{Na}>1$, thus, this transport is sensitive to voltage changes. In both previous (8) and this study (Fig. 1), we showed that total elimination of bath chloride alkalinized the cell, indicating the presence of counter-transport of chloride and bicarbonate. Several mechanisms are considered to account for this exchange. Fig. 10 shows five possible mechanisms (mechanisms 1-5). Mechanism 1 is a direct inhibition of the $\mathrm{Na}-\mathrm{HCO}_{3}$ cotransport by substituting anions for chloride. An inhibition of $\mathrm{Na}-\mathrm{HCO}_{3}$ cotransport will increase $\mathrm{pHi}$. Mechanism 2 predicts that bath chloride removal depolarizes $V \mathrm{bl}$ by a circular current flow generated by a diffusion potential across the tight junction, and this $V \mathrm{bl}$ depolarization inhibits the $\mathrm{Na}-\mathrm{HCO}_{3}$ cotransport since this transport is voltage sensitive. Mechanism 3 is the existence of a chloride conductance in parallel with the $\mathrm{Na}-\mathrm{HCO}_{3}$ cotransport in BLM. If there is a chloride conductance in BLM, a bath chloride removal depolarizes $\mathrm{Vbl}$, and this depolarization inhibits $\mathrm{Na}$ $\mathrm{HCO}_{3}$ cotransport. Mechanism 4 is the parallel existence of the $\mathrm{Na}-\mathrm{HCO}_{3}$ cotransport and $\mathrm{Cl} / \mathrm{HCO}_{3}$ exchange. Mechanism 5 is the parallel existence of the $\mathrm{Na}-\mathrm{HCO}_{3}$ cotransport and $\mathrm{Na}-\mathrm{HCO}_{3} / \mathrm{Cl}$ exchange. The aim of this study was to dif-
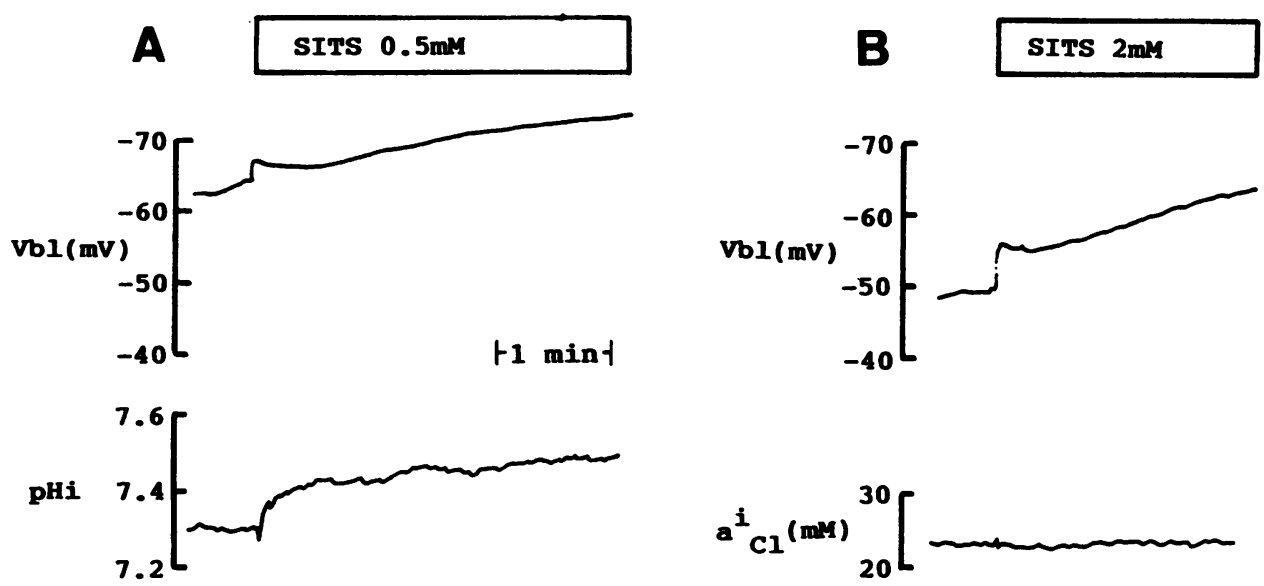

Figure 8. Effect of SITS application to the bath. $(A)$ An application of SITS $(0.5 \mathrm{mM})$ to the bath caused a Vbl hyperpolarization and an increase in $a_{c} i$. (B) An application of SITS $(2 \mathrm{mM})$ to the bath increased bl, but did not change $a_{\mathrm{Cr}}$. 
Table IV. Effect of SITS on pHi and $a_{C l}{ }^{i}$

\begin{tabular}{|c|c|c|c|}
\hline & $\mathrm{Vbl}$ & $\mathrm{pHi}$ & $a_{c}^{i}$ \\
\hline & $m V$ & & $m M$ \\
\hline Control $(n=7)$ & $-53.7 \pm 3.7$ & $7.29 \pm 0.03$ & \\
\hline $\operatorname{SITS}(0.5 \mathrm{mM})$ & $-56.1 \pm 3.8^{*}$ & $7.38 \pm 0.03^{*}$ & \\
\hline Control $(n=8)$ & $-52.3 \pm 3.6$ & & $23.7 \pm 2.1$ \\
\hline $\operatorname{SITS}(0.5 \text { or } 2 \mathrm{mM})^{* *}$ & $-56.3 \pm 3.3^{*}$ & & $24.8 \pm 2.2$ \\
\hline Lumen high $\mathrm{Cl}^{-}(n=4)^{\ddagger}$ & $-49.8 \pm 3.3$ & & $30.0 \pm 1.2$ \\
\hline SITS (1 mM) & $-56.5 \pm 1.7^{*}$ & & $29.9 \pm 1.2$ \\
\hline Bath low $\mathrm{HCO}_{3}^{-}(n=5)^{\S}$ & $-21.0 \pm 2.9$ & & $44.5 \pm 4.8$ \\
\hline SITS $(1 \mathrm{mM})$ & $-36.2 \pm 4.7^{*}$ & & $41.6 \pm 4.6^{*}$ \\
\hline
\end{tabular}

* $P<0.05$.

Values in SITS period are as follows; Vbl value is when it initially hyperpolarized after bath SITS application, and $\mathrm{pHi}$ and $\mathrm{a}_{\mathrm{Cl}}{ }^{\mathrm{i}}$ values are the values at $30 \mathrm{~s}$ after SITS application.

** $0.5 \mathrm{mM}$ SITS was applied in four tubules and in the other four tubules $2 \mathrm{mM}$ SITS was examined. The effects were essentially the same, and the results were gathered.

₹ Luminal perfusate was a low $\mathrm{HCO}_{3}^{-}$, high $\mathrm{Cl}^{-}$and $1 \mathrm{mM}$ formate containing fluid.

${ }^{\S}$ Bath fluid was a low $\mathrm{HCO}_{3}^{-}$and high $\mathrm{Cl}^{-}$solution.

ferentiate these mechanisms, and to define the role of this exchange.

Mechanism 1 can not explain the results that $\mathrm{a}_{\mathrm{Cl}}{ }^{\mathrm{i}}$ increased when bath bicarbonate was reduced (Fig. 3 and Table II). This result is in favor of the existence of chloride/bicarbonate exchange. Mechanism 2 also does not explain some of our data. The decreased $\mathrm{RpHi}$ by chloride removal is not consistent with this mechanism. This mechanism predicts that $\mathrm{RpHi}$ is the same in the presence and absence of ambient chloride. The result that $a_{C l}{ }^{i}$ increased in response to bath bicarbonate reduction can not be explained by mechanism 2 as well.

Mechanism 3, on the other hand, can explain all our data. However, we have not been able to obtain the supportive evidence for a significant basolateral chloride conductance. In our recent study (20), $\mathrm{bl}$ depolarization or hyperpolarization
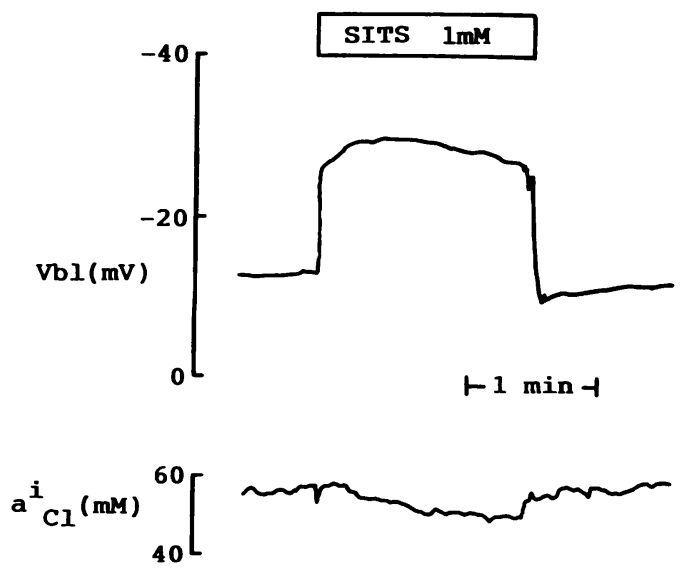

Figure 9. Effect of SITS application on $\mathrm{a}_{\mathrm{C}}{ }^{\mathrm{i}}$ when bath bicarbonate was $5 \mathrm{mM}$. A low bicarbonate solution was used as a bath fluid and SITS $(1 \mathrm{mM})$ was applied to the bath.

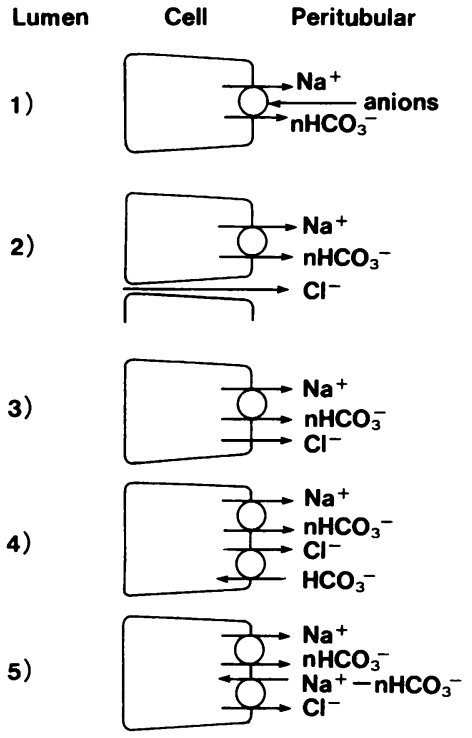

Figure 10. Possible mechanisms that explain the chloride and bicarbonate interaction across the basolateral membrane (see the text for the detail).

caused by a current injection into the tubular lumen through the perfusion pipette changed neither $a_{C l}{ }^{i}$ or $a_{C l}{ }^{i}$ changes in response to bath chloride removal. This result demonstrated that most of basolateral chloride transport in rabbit $S_{2}$ segment is electroneutral. In the present study (Fig. 1) $\mathrm{Vbl}$ depolarized when bath chloride was removed, but the magnitude of the depolarization was small. This small $\mathrm{Vbl}$ depolarization could be easily explained by a circular current flow generated by the chloride diffusion potential across the tight junction as considered previously (8). Thus, a small $\mathrm{Vbl}$ depolarization is in favor of the absence of basolateral chloride conductance, although there is a possibility that $\mathrm{Na}-\mathrm{HCO}_{3} / \mathrm{Cl}$ exchange is electrogenic, and this electrogenicity obscures a chloride-induced depolarization. Our data do not necessarily neglect the existence of small chloride conductance. As a summary, we conclude that there is not a significant chloride conductance in the basolateral membrane.

Both mechanisms 4 and 5 predict the existence of exchange of chloride and bicarbonate in $\mathrm{BLM}$ : one is a pure $\mathrm{Cl} / \mathrm{HCO}_{3}$ exchange (mechanism 4), and the other is a sodium coupled $\mathrm{Cl} / \mathrm{HCO}_{3}$ exchange, possibly $\mathrm{Na}-\mathrm{HCO}_{3} / \mathrm{Cl}$ exchange (mechanism 5). The chloride/bicarbonate exchange would explain all our data. To differentiate whether the exchange is coupled to sodium, the response of $\mathrm{a}_{\mathrm{c}}{ }^{i}$ to bath bicarbonate reduction was examined in the absence of sodium (Fig. 4 and Table III). The result clearly demonstrated that the most of $\mathrm{Cl} / \mathrm{HCO}_{3}$ exchange is dependent on sodium (mechanism 5). The small increase in $\mathrm{a}_{\mathrm{C}}{ }^{\mathrm{i}}$ in response to bath bicarbonate reduction in sodium free condition (Fig. 4) may indicate the existence of sodium independent $\mathrm{Cl} / \mathrm{HCO}_{3}$ exchange (mechanism 4 ), although the possibility exists that a small amount of residual intracellular sodium drives the $\mathrm{Na}-\mathrm{HCO}_{3} / \mathrm{Cl}$ exchange. The result that total chloride removal reduced the $\mathrm{RpHi}$ induced by bath sodium removal is also against mechanism 4 . If a pure $\mathrm{Cl} / \mathrm{HCO}_{3}$ exchange exists in parallel to the $\mathrm{Na}-\mathrm{HCO}_{3}$ cotransport, the $\mathrm{Cl} / \mathrm{HCO}_{3}$ exchange will compensate $\mathrm{pHi}$ changes caused by a bath sodium withdrawal. Thus, total chloride removal is expected to exaggerate $\mathrm{RpHi}$, which is induced by bath sodium removal (contrast to our observation). As a summary of the above discussion, we conclude that $\mathrm{Na}-\mathrm{HCO} / \mathrm{Cl}$ 
exchange is a major mechanism for the interaction between chloride and bicarbonate in BLM of rabbit PST.

Chloride/bicarbonate exchange in BLM. We conclude that a sodium coupled $\mathrm{Cl} / \mathrm{HCO}_{3}$ exchange mechanism exists in BLM of rabbit PST ( $S_{2}$ segment). This kind of transport systems has been examined in other cells. An electroneutral Na$\mathrm{HCO}_{3} / \mathrm{Cl}-(\mathrm{H})$ exchange mechanism has been demonstrated in invertebrate nonepithelial cells such as the snail neuron (9), barnacle muscle (11), and squid giant axon (10). This mechanism has been identified as an acid extrusion mechanism when the cells were acid loaded ( $\mathrm{Na}-\mathrm{HCO}_{3}$ influx and $\mathrm{Cl}-(\mathrm{H})$ efflux). An apparently similar transport system was also identified in the cultured fibroblasts of hamster (12). In the epithelial cells, Guggino et al. recently identified the $\mathrm{Na}-\mathrm{HCO}_{3} / \mathrm{Cl}$ exchange in BLM of Necturus proximal tubule (13). They concluded that this mechanism is the major route for chloride movement across BLM in their preparation. Alpern reported the possible existence of sodium dependent $\mathrm{Cl} / \mathrm{HCO}_{3}$ exchange mechanism in BLM of rat PCT (17). Vesicle studies in the rat kidney (21), and not in the rabbit kidney (22) have presented evidence for $\mathrm{Na}-\mathrm{HCO}_{3} / \mathrm{Cl}$ exchange. The demonstration of $\mathrm{Na}-\mathrm{HCO}_{3} /$ $\mathrm{Cl}$ exchange in the present study strengthens the view that this kind of transport mechanism prevails in many kinds of cells.

Although we identified the $\mathrm{Na}-\mathrm{HCO}_{3} / \mathrm{Cl}$ exchange mechanism in BLM of rabbit PST, we have to admit that we did not clarify the characteristics of this exchanger. We could not determine even the electrogenicity of this system. This difficulty was clearly due to the coexistence of the $\mathrm{Na}-\mathrm{HCO}_{3}$ cotransporter, which is electrogenic, and possesses a higher transport activity. Any change that is due to the $\mathrm{Na}-\mathrm{HCO}_{3} / \mathrm{Cl}$ exchange could be easily masked by a dominant $\mathrm{Na}-\mathrm{HCO}_{3}$ cotransporter. Further studies are needed to identify the stoichiometry, and the true substrate of this exchanger.

We observed a small increase in $a_{C l}{ }^{i}$ in response to bath bicarbonate reduction in the absence of ambient sodium (Fig. 4) which is consistent with a sodium independent $\mathrm{Cl} / \mathrm{HCO}_{3}$ exchange. The sodium independent $\mathrm{Cl} / \mathrm{HCO}_{3}$ exchange mechanism has been shown in other epithelial preparations $(19,22$, 23). In our sodium free condition the possibility exists that a small amount of sodium remains in the cell, and that this sodium drives the $\mathrm{Na}-\mathrm{HCO}_{3} / \mathrm{Cl}$ exchange. At any rate we can safely conclude that the contribution of sodium independent $\mathrm{Cl} / \mathrm{HCO}_{3}$ exchange is very small in the rabbit $\mathrm{S}_{2}$ segment.

The role of $\mathrm{Na}-\mathrm{HCO}_{3} / \mathrm{Cl}$ exchange. If we assume that the stoichiometry of the $\mathrm{Na}-\mathrm{HCO}_{3} / \mathrm{Cl}$ exchange of rabbit PST is similar to that of cells from invertebrates, i.e., $\mathrm{Na}-2 \mathrm{HCO}_{3} / \mathrm{Cl}$ (electroneutral), we can tell the direction of the exchanger by calculating the driving force. The energy for the electroneutral $\mathrm{Na}-2 \mathrm{HCO}_{3} / \mathrm{Cl}$ exchange across BLM can be given as

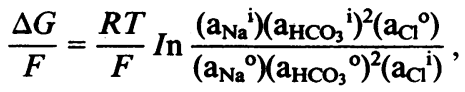

where $\Delta G$ is the free energy change, and $F, R$, and $T$ are their usual meanings. $a_{x}{ }^{i}$ and $a_{x}{ }^{\circ}$ are the ionic activity of $X$ in the cell and bath, respectively. A negative value of $G$ means the influx of sodium and bicarbonate, and efflux of chloride out of the cell. Putting the intracellular ionic activity values in the control condition determined in the previous (8) and present studies to Eq. $2\left(a_{\mathrm{Na}}{ }^{\mathrm{i}} 47 \mathrm{mM}, \mathrm{a}_{\mathrm{HCO}_{3}}{ }^{i} 11 \mathrm{mM}, \mathrm{a}_{\mathrm{Cl}}{ }^{\mathrm{i}} 21 \mathrm{mM}\right), \Delta G / F$ of $-11 \mathrm{mV}$ is obtained. Thus, if this stoichiometry is the case, this transporter is expected to work as a chloride extruding and
$\mathrm{Na}-\mathrm{HCO}_{3}$ loading mechanism in the control condition. The latter component may easily be compensated by the dominant $\mathrm{Na}-\mathrm{HCO}_{3}$ cotransporter.

To determine the validity of this speculation, we applied SITS to the bath and immediate changes in $\mathrm{pHi}$ and $\mathrm{a}_{\mathrm{C}}{ }^{\mathrm{i}}$ were monitored. Since we demonstrated the parallel existence of two SITS sensitive transporters, namely, $\mathrm{Na}-\mathrm{HCO}_{3}$ cotransport and $\mathrm{Na}-\mathrm{HCO}_{3} / \mathrm{Cl}$ exchange, if the sum of bicarbonate fluxes mediated by these transporters is bicarbonate efflux out of the cell, SITS application will alkalinize the cell. Similarly, if chloride flux mediated by the $\mathrm{Na}-\mathrm{HCO}_{3} / \mathrm{Cl}$ exchange is a chloride efflux, SITS application is expected to increase $a_{C l}{ }^{i}$. Our results (Fig. 8) clearly showed that addition of SITS increased $\mathrm{pHi}$, but did not change $\mathrm{a}_{\mathrm{cl}} \mathrm{i}$. This fact demonstrated that the net flux of bicarbonate across BLM is bicarbonate efflux that is mainly mediated by the $\mathrm{Na}-\mathrm{HCO}_{3}$ cotransport, and implied that the basolateral chloride flux mediated by the $\mathrm{Na}-\mathrm{HCO} / \mathrm{Cl}$ exchange is very small. The application of SITS did not change $a_{C}{ }^{i}$ even in the condition where the transcellular chloride flux was augmented by perfusing tubular lumen with a high chloride and formate containing solution, indicating that the $\mathrm{Na}$ $\mathrm{HCO}_{3} / \mathrm{Cl}$ exchange might not be the main route for basolateral chloride exit. Other mechanisms besides the $\mathrm{Na}-\mathrm{HCO}_{3} / \mathrm{Cl}$ exchange, such as $\mathrm{K}-\mathrm{Cl}$ symport $(20,24,25)$ may contribute to basolateral chloride transport. However, the lack of short term effect of SITS on $a_{\mathrm{C}}{ }^{i}$ does not necessarily indicate the absence of basolateral chloride transport. Our present interpretation depends on the assumption that the apical chloride entry continues after basolateral transport is blocked. If this assumption is not true, then it is impossible to speculate transcellular chloride flux by monitoring the changes in $\mathrm{a}_{\mathrm{Cl}}{ }^{\mathrm{i}}$. It might be possible that chloride transport across the luminal and basolateral membrane is functionally coupled, thus, preventing an acute change in $a_{C}{ }^{i}$. Such functional coupling of solute transport across the two membranes has been considered for sodium $(26,27)$. Further study is required to examine this possibility.

Our results indicate that $\mathrm{Na}-\mathrm{HCO}_{3} / \mathrm{Cl}$ exchange contributes to the basolateral bicarbonate efflux when the basolateral bicarbonate transport is stimulated. This was shown by the fact that the $\mathrm{RpHi}$ induced by bath bicarbonate reduction was slowed by removal of chloride (Fig. 5), and that $\mathrm{a}_{\mathrm{Cl}}{ }^{\mathrm{i}}$ decreased when SITS was applied to the low bicarbonate bath solution (Fig. 9, and Table IV).

Speculation regarding the role of the $\mathrm{Na}-\mathrm{HCO}_{3} / \mathrm{Cl}$ exchange in physiologic conditions may be interesting. As discussed above, this exchange works as a bicarbonate exit mechanism as proximal bicarbonate reabsorption is stimulated. This stimulation of the basolateral bicarbonate efflux increases $a_{C C}{ }^{i}$, which in turn will inhibit the uptake of chloride across the luminal membrane. The net effect is that a stimulation of bicarbonate reabsorption inhibits transcellular chloride reabsorption. Thus, $\mathrm{Na}-\mathrm{HCO}_{3} / \mathrm{Cl}$ exchange may work to keep the total transport rates of anions (chloride + bicarbonate) across BLM constant in the proximal tubule. For example, hypercapnia has been known to induce chloruresis (28). Micropuncture studies in the rat observed that acute hypercapnia stimulates bicarbonate reabsorption and inhibits chloride reabsorption in PCT $(29,30)$. Cogan concluded that this inhibition of chloride absorption occurred on transcellular chloride absorption (30). The existence of $\mathrm{Na}-\mathrm{HCO}_{3} / \mathrm{Cl}$ exchange may fit with this interaction of chloride and bicarbonate. A stimulation of bicarbonate absorption by hypercapnia (exact 
mechanisms not known) causes an increase in bicarbonate efflux across BLM. This increased efflux may be handled in part by the $\mathrm{Na}-\mathrm{HCO}_{3} / \mathrm{Cl}$ exchange, and this causes an increase in $a_{C l}{ }^{i}$. An increase in $a_{C l}{ }^{i}$ will inhibit the luminal chloride uptake mechanism leading to the inhibition of the transcellular chloride reabsorption. Thus, it is conceivable that the $\mathrm{Na}-$ $\mathrm{HCO}_{3} / \mathrm{Cl}$ exchange may play a role when basolateral bicarbonate and chloride fluxes are altered in several physiologic conditions.

\section{Acknowledgments}

We are grateful to Dr. M. Imai, and Dr. K. Yoshitomi for critically reading the manuscript. We thank Drs. T. Shiigai, Y. Iino, and K. Tomita for encouragement of this work.

This study was supported by a Grant-in-Aid from Ministry of Education, Science, and Culture, Japan.

\section{References}

1. Boron, W. F., and E. L. Boulpaep. 1983. Intracellular pH regulation in the renal proximal tubule of the salamander. Basolateral $\mathrm{HCO}_{3}^{-}$ transport. J. Gen. Physiol. 81:53-94.

2. Biagi, B. A. 1985. Effects of the anion transport inhibitors, SITS, on the proximal straight tubule of the rabbit perfused in vitro. $J$. Membr. Biol. 88:25-31.

3. Biagi, B. A., and M. Sohtell. 1986. Electrophysiology of basolateral bicarbonate transport in the rabbit proximal tubule. Am. J. Physiol. 250 (Renal Fluid Electrolyte Physiol. 19):F267-F272.

4. Yoshitomi, K., B.-Ch. Burckhardt, and E. Fromter. 1985. Rheogenic sodium-bicarbonate cotransport in the peritubular cell membrane of rat renal proximal tubule. Pfluegers Arch. Eur. J. Physiol. 405:360-366.

5. Alpern, R. J. 1985. Mechanism of basolateral membrane $\mathrm{H}^{+} / \mathrm{OH}^{-} / \mathrm{HCO}_{3}^{-}$transport in the rat proximal convoluted tubule. A sodium-coupled electrogenic process. J. Gen. Physiol. 86:613-636.

6. Jentsch, T. J., B. S. Schill, P. Schwartz, H. Matthes, S. K. Keller, and M. Wiederholt. 1985. Kidney epithelial cells of monkey origin (BSC-1) express a sodium bicarbonate cotransport. J. Biol. Chem. 260:15554-15560.

7. Sasaki, S., T. Shiigai, and J. Takeuchi. 1985. Intracellular pH in the isolated perfused rabbit proximal straight tubule. Am. J. Physiol. 249 (Renal Fluid and Electrolyte Physiol. 18):F417-F423.

8. Sasaki, S., T. Shiigai, N. Yoshiyama, and J. Takeuchi. 1987. Mechanism of bicarbonate exit across basolateral membrane of rabbit proximal straight tubule. Am. J. Physiol. 252 (Renal Fluid Electrolyte Physiol. 21):F11-F18.

9. Thomas, R. C. 1977. The role of bicarbonate, chloride and sodium ions in the regulation of intracellular $\mathrm{pH}$ in snail neurones. $J$. Physiol. 273:317-338.

10. Boron, W. F., and J. M. Russel. 1983. Stoichiometry and ion dependencies of the intracellular-pH-regulating mechanism in squid giant axons. J. Gen. Physiol. 81:373-399.

11. Boron, W. F., W. C. McCormick, and A. Roos. 1981. pH regulation in barnacle muscle fibers: dependence on extracellular sodium and bicarbonate. Am. J. Physiol. 240 (Cell Physiol. 9):C80-C89.

12. L'Allemain, G., S. Paris, and J. Pouyssegur. 1984. Role of a
Na-dependent $\mathrm{Cl} / \mathrm{HCO}_{3}$ exchange in regulation of intracellular $\mathrm{pH}$ in fibroblasts. J. Biol. Chem. 259:5809-5815.

13. Guggino, W. B., R. London, E. L. Boulpaep, and G. Giebisch. 1983. Chloride transport across the basolateral cell membrane of the necturus proximal tubule: dependence on bicarbonate and sodium. $J$. Membr. Biol. 71:227-240.

14. Burg, M. B., J. Grantham, M. Abramow, and J. Orloff. 1966. Preparation and study of fragments of single rabbit nephrons. Am. J. Physiol. 210:1293-1298.

15. Ammann, D., F. Lanter, R. A. Steiner, P. Schulthess, Y. Shijo, and W. Simon. 1981. Neutral carrier based hydrogen ion selective microelectrode for extra- and intracellular studies. Anal. Chem. 53:2267-2269.

16. Ishibashi, K., S. Sasaki, N. Yoshiyama, T. Shiigai, and J. Takeuchi. 1987. Intracellular chloride activity of rabbit proximal straight tubules. Kidney Int. 31:437a. (Abstr.)

17. Alpern, R. J., and M. Chambers. 1986. Sodium dependent $\mathrm{Cl} / \mathrm{HCO}_{3}$ exchange on the basolateral membrane of the rat proximal convoluted tubules. Clin. Res. 34:587a. (Abstr.)

18. Schild, L., G. Giebisch, L. P. Karniski, and P. S. Aronson. 1987. Effect of formate on volume reabsorption in the rabbit proximal tubule. J. Clin. Invest. 79:32-38.

19. Jentsch, T. J., I. Janiche, D. Sorgenfrei, S. K. Keller, and M. Wiederholt. 1986. The regulation of intracellular $\mathrm{pH}$ in monkey kidney epithelial cells (BSC-1). J. Biol. Chem. 261:12120-12127.

20. Sasaki, S., K. Ishibashi, N. Yoshiyama, and T. Shiigai. 1988. $\mathrm{KCl}$ cotransport across the basolateral membrane of rabbit renal proximal straight tubules. J. Clin. Invest. 81:194-199.

21. Grassl, S. M., P. D. Holohan, and C. R. Ross. $1987 . \mathrm{HCO}_{3}$ transport in basolateral membrane vesicles isolated from rat renal cortex. J. Biol. Chem. 262:2682-2687.

22. Grassl, S. M., and P. S. Aronson. 1986. Na/HCO 3 cotransport in basolateral membrane vesicles isolated from rabbit renal cortex. $J$. Biol. Chem. 261:8778-8783.

23. Chaillet, J. R., K. Amsler, and W. F. Boron. 1986. Optical measurements of intracellular $\mathrm{pH}$ in single $\mathrm{LLC}^{-\mathrm{PK}_{1}}$ cells: demonstration of Cl- $-\mathrm{HCO}_{3}$ exchange. Proc. Natl. Acad. Sci. USA. 83:522-526.

24. Reuss, L. 1983. Basolateral $\mathrm{KCl}$ co-transport in a $\mathrm{NaCl}$-absorbing epithelium. Nature (Lond.). 305:723-726.

25. Eveloff, J., and D. G. Warnock. 1987. KCl transport systems in rabbit renal basolateral membrane vesicles. Am. J. Physiol. 252 (Renal Fluid Electrolyte Physiol. 21):F883-F889.

26. Schultz, S. G. 1981. Homocellular regulatory mechanisms in sodium-transporting epithelia: avoidance of extinction by "flushthrough." Am. J. Physiol. 241 (Renal Fluid Electrolyte Physiol. 10):F579-F590.

27. Diamond, J. M. 1982. Transcellular cross-talk between epithelial cell membranes. Nature (Lond.). 300:683-685.

28. Levitin, H., W. Branscome, and F. H. Epstein. 1958. The pathogenesis of hypochloremia in respiratory acidosis. J. Clin. Invest. 37:1667-1675.

29. Warren, Y., R. G. Luke, M. Kashgarian, and H. Levitin. 1970. Micropuncture studies of chloride and bicarbonate absorption in the proximal renal tubule of the rat in respiratory acidosis and in chloride depletion. Clin. Sci. 38:375-383.

30. Cogan, M. G. 1984. Effect of acute alterations in $\mathrm{PCO}_{2}$ on proximal $\mathrm{HCO}_{3}, \mathrm{Cl}$, and $\mathrm{H}_{2} \mathrm{O}$ reabsorption. Am. J. Physiol. 246 (Renal Fluid Electrolyte Physiol. 15):F21-F26. 